\title{
Prevalent skin and dermatoses care in older adults treated at a private clinic and its relationship with comorbidities
}

Ana Carolina Marianil (ID

Fernanda Santos Pozzi ${ }^{2}$ ID Jane de Eston Armond' $\mathbb{1}$ Carmen Guilherme Christiano de Matos Vinagrel $\mathbb{I D}^{\mathrm{D}}$

\section{Abstract}

Objectives: To identify and assess the prevalence of skin changes in the older adults surveyed, as well as to detect skin phototype according to the Fitzpatrick classification and to assess whether there was an association between the changes identified and predisposing factors (smoking, diabetes mellitus and hypertension). Additionally, evaluate the level of knowledge of the subjects regarding skin care. Method: A cross-sectional study was conducted in April to August 2018, based on a convenience sample of 80 older adults attending a private clinic. A questionnaire was applied among the subjects to identify their skin care and an answer sheet was completed by the researcher with information about the physical examination of the skin. Data were analyzed by the chi square or Fisher's exact method. Poisson regression was used to determine the independent effect of the exploratory variables on the response variable. Results: The sampled population had a low level of education and was low-income and did not take proper care of their skin, while $70 \%$ were skin phototype 4 . Most $(73 \%)$ were aware of what skin cancer is and a significant portion $50 \%$ did not use sunscreen or moisturizer. There was no significant difference between the sexes $(p>0.05)$. About half of the older adults reported having been instructed about skin care. Seventy two percent knew about the dangers of sun exposure. The most common skin alteration was melanosis and an association was found between diabetes and keratosis. Conclusions: The study population was low income, with a low level of education. They were exposed to the sun and did not make proper use of sunscreen or moisturizers, but sought health information from their doctor and knew what skin cancer was.
Keywords: Aging. Skin Aging. Skin Diseases. Diabetes Mellitus.

\footnotetext{
Universidade de Santo Amaro, Departamento de Ciências da Saúde, Programa de pós-graduação em Ciências da Saúde, São Paulo, SP, Brasil.

2 Instituto de Pesquisa e Educação em Saúde de São Paulo, Programa de pós graduação em Biomedicina e Farmácia Estética, São Paulo, SP, Brasil.
}

The authors declare there are no conflicts of interest in relation to the present study.

No funding was received in relation to the present study. 


\section{INTRODUCTION}

Many studies have sought to address population aging from different perspectives, however, skin aging, considered from the point of view of older adults themselves, has still not been addressed ${ }^{1}$.

Skin aging is a complex and multifactorial phenomenon. There is no single explanation for this process and many aspects remain unknown ${ }^{2}$. Its complexity is due to the structure of the skin itself, which is composed of the epidermis, dermis, extracellular matrix, vascular structures and skin annexes $^{2}$. At 65 years of age, the dermis loses structure, becoming flat, and there is a decrease in cell proliferation, leading to greater susceptibility to trauma and penetration by infectious agents ${ }^{3}$.

The chronic diseases that affect older adults, especially diabetes, can predispose them to lesions ${ }^{4}$, however, they also have to deal with many other skin disorders such as purpura and senile melanosis, many of which are confused with diseases.

In view of all the physiological changes of aging ${ }^{5}$ which affect about $40 \%$ of this population and contribute to the occurrence of lesions on the skin of older adults, such as dryness, itching, calluses, vesicles, blisters, ulcers, benign and malignant tumors, it is important that this population is aware of the care required to prevent skin diseases ${ }^{6}$ such as melanomas, carcinomas and senile keratosis.

The aim of the present study was to identify and assess the prevalence of skin disorders in the older adults surveyed, as well as to detect skin phototype according to the Fitzpatrick classification and to assess whether there was an association between the disorders exhibited and predisposing factors (smoking, diabetes mellitus and arterial hypertension). The level of knowledge of the older adults in relation to skin care was also assessed.

\section{METHOD}

An observational, cross-sectional, descriptive and analytical study was carried out. Cross-sectional studies are useful to describe variables and their distribution patterns and allow the prevalence of a phenomenon of interest to be identified, complying with the objectives of this research.

The study was carried out from April to June 2018 in a clinic located in the west of Greater São Paulo, Brazil, a region with a subtropical climate. The clinic is multi-specialty in nature and serves health plan users. The population attending the clinic is heterogeneous, taken from all socioeconomic levels, with dermatology care carried out under authorization from the patient's medical insurance provider.

The sample consisted of 80 older adults attending the clinic. This number was reached in the proposed period of data collection (April to June 2018).

To calculate the sample size, the public domain program OpenEpi, version $3.01^{7}$ was used. The calculation was based on a study involving 75 institutionalized older adults, where a high prevalence $(98 \%)$ of injuries related to cutaneous senescence was observed ${ }^{8}$. Since almost half of the patients $(48 \%)$ in the aforementioned study were aged 80 years or older, a prevalence of $32 \%$ for the present study was estimated.

The older adults were recruited and preliminary detailed information regarding the protocol was given to the participants before the beginning of the study. All signed an Informed Consent Form in accordance with Resolution No. 466/2012 and Resolution No. 510/2016, under ethics committee opinion number 2,583,019.

The inclusion criteria were older adults over 60 years old. The exclusion criteria adopted were illiteracy and dementia and psychiatric conditions, due to the difficulty of responding to the study by clinical diagnosis.

A semi-structured questionnaire was used to outline the profile and knowledge of the older adults in relation to skin aging.

A patient care form was also filled out, consisting of two multiple-choice items, one to define the patient's skin phototype and the other with the skin disorders found'. The skin diseases found were properly handled and the older adults were 
also instructed on their clinical condition and care. The older adults were assessed using the Fitzpatrick classification, according to the reaction of the skin to sun exposure? ${ }^{9}$ This classification was created by a dermatologist to classify skin types according to their behavior in relation to sun exposure, with the higher the phototype (4 and 5) the more tanned the skin when it is exposed to the sun.

The data collected were socio-demographic in nature, namely: age, sex, city of birth, city in which older adult resides, income, type of income (salaried or pension) and level of education. Data regarding previous health were also obtained, namely: current diseases and current or previous smoker (one of the main factors of extrinsic skin aging).

The categorical variables were summarized by means of absolute and relative frequencies and the continuous variables through medians and interquartile range (IQR), after verifying the absence of normal distribution by the Shapiro-Wilk test, which makes it impossible to use means due to the asymmetry of the data.

The Chi-square test or Fisher's exact test were used to assess the existence of statistical differences between the categorical variables and the prevalence ratio (PR) was used as a measure of the strength of this association. To determine the independent effect of the exploratory variables on the response variable, Poisson regression with robust variance was used to adjust the covariates. The variables selected for this model had a value of $p<0.20$ in the bivariate analysis or biological plausibility.

For Poisson regression, the amount of skin disorders identified in the older adults evaluated was dichotomized in up to two and three or more and was considered as an outcome in the bivariate and multivariate analyzes. The variable sun exposure was dichotomized as yes/no. Those who answered yes were asked about the time of exposure, with the answer options being in the morning before $10 \mathrm{am}$, after $10 \mathrm{am}$ and before noon, between $1 \mathrm{pm}$ and $4 \mathrm{pm}$ and after $4 \mathrm{pm}$ and no when the option selected was I don't expose myself to the sun. The question use of sunscreen was dichotomized as yes/no. Those who answered yes were asked about frequency, with the options being always use and sometimes use and no when the answer was don't use.
The skin hydration variable was dichotomized as yes/no. Those who answered yes were asked about frequency, with the options being daily and rarely/ sometimes and no when the answer was I don't usually use it. The variable given information on skin cancer in the last 6 months was dichotomized as yes/no. Those who answered yes were asked from which source, with the options being television, newspapers and magazines, medical consultation, family or health clinic campaign and no when the answer was I did not have access to information.

\section{RESULTS}

The most prevalent comorbidity was systemic arterial hypertension which affected 57 older adults (71.25\%). Only 11 individuals had diabetes (13.75\%).

Only two (3\%) older adults admitted that they smoked, while 13 (15\%) said they were ex-smokers and $65(82 \%)$ reported that they had never smoked.

Regarding guidelines on skin care, 42 (52.5\%) older adults reported having received such guidance, while $38(47.5 \%)$ reported not having received such instructions. It was observed that $58(72.5 \%)$ study participants were aware of the dangers of being exposed to solar radiation and only $22(27.5 \%)$ were unaware. It was also observed that just over half of the studied population, 43 older adults (53.8\%), had been exposed to the sun, while $37(46.2 \%)$ had not been exposed. Regarding the use of sunscreen, $43(53.75 \%)$ used it, while $37(46.25 \%)$ reported not using it. In the sample, $59(73.75 \%)$ of the older adults reported knowing what skin cancer was and, $21(26.25 \%)$ said they did not know. Regarding the Fitzpatrick classification, $56(70 \%)$ of the study participants had skin phototype 4 . Regarding skin hydration, in the total sample, 46 (47.5\%) reported using some type of moisturizer while 34 (42.5\%) did not use one.

After physical examination of the skin, the main skin pathologies found in the sample were also assessed, as shown in Table 1.

The factors associated with the number of skin disorders in the older adults were assessed by bivariate analysis as shown in table 2 . 
Table 1. Main skin pathologies in older adults (N=80). Jandira, Sao Paulo, 2018.

\begin{tabular}{lllll}
\hline Disease/Disorder & Male & Female & * $p$ value & $\begin{array}{l}\text { Total } \\
\mathrm{N}(\%)\end{array}$ \\
\hline Xerosis & $\mathrm{N}(\%)$ & $19(47.5)$ & 0.07 & $47(58.75)$ \\
\hline Melanosis & $39(70)$ & $33(82.5)$ & 0.06 & $72(90)$ \\
\hline Spinocellular carcinoma & $01(2.5)$ & $0(0)$ & 1 & $01(1.25)$ \\
\hline Purpura & $07(17.5)$ & $09(22.5)$ & 0.78 & $16(20)$ \\
\hline Actinic keratosis & $03(7.5)$ & $07(17.5)$ & 0.31 & $10(12.5)$ \\
\hline Seborrheic keratosis & $03(7.5)$ & $07(17.5)$ & 0.31 & $10(12.5)$ \\
\hline Onychomycosis & $11(27.5)$ & $07(17.5)$ & 0.42 & $18(22.5)$ \\
\hline Tinea & $05(12.5)$ & $01(2.5)$ & 0.2 & $06(7.5)$ \\
\hline Acrochordon & $03(7.5)$ & $01(2.5)$ & 0.62 & $04(5)$ \\
\hline Common Wart & $01(2.5)$ & $0(0)$ & 1 & $01(1.25)$ \\
\hline Bowenoid papulosis & $0(0)$ & $03(7.5)$ & 0.24 & $03(3.75)$ \\
\hline
\end{tabular}

* Fisher's Exact Test, $p<0.05$.

Table 2. Bivariate analysis of factors associated with the number of skin disorders in older adults with dermatoses treated in Jandira, Sao Paulo.

\begin{tabular}{|c|c|c|c|}
\hline Characteristics & $\begin{array}{l}\text { Skin disorders } \\
\mathrm{N}(\%)\end{array}$ & Crude-PR (CI95\%) & ${ }^{*} p$-value \\
\hline \multicolumn{4}{|l|}{ Sex } \\
\hline Male & $40(50)$ & $1.93(1.20-3.09)$ & 0.004 \\
\hline Female & $40(50)$ & 1.00 & \\
\hline \multicolumn{4}{|c|}{ Family income (minimum wage) } \\
\hline Up to 2 & $79(98.75)$ & 1.00 & \\
\hline 3 to 5 & $1(1.25)$ & - & - \\
\hline \multicolumn{4}{|c|}{ Education (years of study) } \\
\hline 1 to 4 & $74(92.5)$ & 1.00 & \\
\hline 5 to 8 & $6(7.5)$ & $0.63(0.20-2.00)$ & 0.36 \\
\hline \multicolumn{4}{|c|}{$\begin{array}{l}\text { Received skin care guidance } \\
\text { from a health professional }\end{array}$} \\
\hline Yes & $42(52.5)$ & $0.86(0.56-1.32)$ & 0.49 \\
\hline No & $38(27.5)$ & 1.00 & \\
\hline \multicolumn{4}{|c|}{ Health professional who provided guidance } \\
\hline Doctor & $41(51.25)$ & - & - \\
\hline Nurse & $1(1.25)$ & 1.00 & \\
\hline \multicolumn{4}{|c|}{$\begin{array}{l}\text { Knows the dangers of exposing } \\
\text { oneself to the sun }\end{array}$} \\
\hline Yes & $58(72.5)$ & $0.66(0.44-0.98)$ & 0.06 \\
\hline No & $22(27.5)$ & 1.00 & \\
\hline
\end{tabular}


Continuation of Table 2

\begin{tabular}{|c|c|c|c|}
\hline Characteristics & $\begin{array}{l}\text { Skin disorders } \\
\mathrm{N}(\%)\end{array}$ & Crude-PR (CI95\%) & ${ }^{*} p$-value \\
\hline \multicolumn{4}{|l|}{ Exposure to the sun } \\
\hline Yes & $43(53.75)$ & $0.90(0.59-1.38)$ & 0.64 \\
\hline Before $10 \mathrm{~h}$ & $40(50)$ & & \\
\hline Between $10 \mathrm{~h}$ and $12 \mathrm{~h}$ & $1(1.25)$ & & \\
\hline Between $13 \mathrm{~h}$ and $16 \mathrm{~h}$ & $2(2.5)$ & & \\
\hline After $16 \mathrm{~h}$ & $0(0)$ & & \\
\hline No & $37(46.25)$ & 1.00 & \\
\hline \multicolumn{4}{|l|}{ Uses sunscreen } \\
\hline Yes & $44(55)$ & $0.86(0.56-1.31)$ & 0.48 \\
\hline No & $36(45)$ & 1.00 & \\
\hline \multicolumn{4}{|l|}{ Uses skin moisturizer } \\
\hline Yes & $46(57.5)$ & $0.70(0.46-1.07)$ & 0.10 \\
\hline No & $34(42.5)$ & 1.00 & \\
\hline \multicolumn{4}{|c|}{$\begin{array}{l}\text { Used ointment, lotion or skin } \\
\text { product without medical advice }\end{array}$} \\
\hline Yes & $80(100)$ & - & - \\
\hline No & $0(0)$ & 1.00 & \\
\hline \multicolumn{4}{|c|}{ Knows what skin cancer is } \\
\hline Yes & $59(73.75)$ & $0.86(0.54-1.35)$ & 0.53 \\
\hline No & $21(26.25)$ & 1.00 & \\
\hline \multicolumn{4}{|c|}{$\begin{array}{l}\text { Had access to information about } \\
\text { cancer in the last } 6 \text { months }\end{array}$} \\
\hline Yes & $24(30)$ & $1.35(0.88-2.04)$ & 0.19 \\
\hline No & $56(70)$ & 1.00 & \\
\hline \multicolumn{4}{|c|}{ Total number of comorbidities } \\
\hline One & $60(75)$ & 1.00 & \\
\hline Two or more & $2(2.5)$ & $1.24(0.79-1.93)$ & 0.37 \\
\hline \multicolumn{4}{|c|}{ Systemic arterial hypertension } \\
\hline Yes & $55(68.75)$ & $1.10(0.68-1.78)$ & 0.69 \\
\hline No & $25(31.25)$ & 1.00 & \\
\hline \multicolumn{4}{|l|}{ Diabetes mellitus } \\
\hline Yes & $11(13.75)$ & $1.76(1.21-2.57)$ & 0.03 \\
\hline No & $69(86.25)$ & 1.00 & \\
\hline \multicolumn{4}{|l|}{ Thyroid disease } \\
\hline Yes & $8(10)$ & $0.71(0.28-1.78)$ & 0.41 \\
\hline No & $72(90)$ & 1.00 & \\
\hline \multicolumn{4}{|l|}{ Phototype } \\
\hline $1-3$ & $10(12.5)$ & 1.00 & \\
\hline $4-5$ & $70(87.5)$ & $1.02(0.53-1.99)$ & 0.93 \\
\hline
\end{tabular}

* Chi-squared test. $p<0.05$. 
There was no statistical association between diabetes and xerosis $(p=0.18)$, melanosis $(p=0.23)$, carcinoma $(p=0.57)$, senile purpura $(p=0.51)$, onychomycosis $(p=0.28)$, tinea $(p=0.82)$ or acrochordon $(p=0.50)$, but there was an association with keratosis (PR, 2.21; 95\% CI, 1.12-4.36; $p=0.04$ ).

There was no statistical association between smoking and xerosis $(p=0.14)$, melanosis $(p=0.63)$, carcinoma $(p=0.75)$, senile purpura $(p=0.47)$, keratosis $(p=0,66)$, onychomycosis $(p=0.12)$, tinea $(p=0.89)$ or acrochordon $(p=0.10)$.

There was no statistical association between systemic arterial hypertension and xerosis $(p=0.14)$, melanosis $(p=0.22)$, carcinoma $(p=0.56)$, senile purpura ( $p=0.54)$, keratosis $(p=0.66)$, onychomycosis $(p=0.11)$, tinea $(p=0.89)$ or acrochordon $(p=0.40)$.

\section{DISCUSSION}

Approximately half of the older population evaluated reported that they had never received guidance in relation to care methods for the prevention of skin diseases. Considering that everyone has had a medical appointment at least once in their lives, it is worrying that almost half of these older adults had not been educated about skin care, especially since most had some comorbidity that caused disorders in their skin.

According to the Fitzpatrick ${ }^{10}$ classification, the older people evaluated in the present study had skin phototype 4, which represents a lower incidence of sunburn, injuries and skin cancer, as the darker the skin (the greater melanosome activity), the less sensitive it is, and the lower the risk of developing injuries.

The prevalence of smokers, whether current or previous, was low among the older adults in the present study. There is a consensus that smoking is one of the main extrinsic skin aging agents, with deteriorating elasticity, loss of collagen and the formation of free radicals ${ }^{11}$.

Regarding exposure to the sun, most of the older adults said they were aware of the dangers arising from this exposure and of the skin care required. However, it is still worrying that $22 \%$ of the older adults in the sample were not aware of the dangers of being exposed to the sun, since solar radiation can cause burns, aging and predispose to skin cancer ${ }^{12,13}$ which is common in this age group.

Among cancers, there is a greater predisposition for the development of basal cell carcinoma and squamous cell carcinoma in aging. These do not cause mortality, but alter quality of life, as the treatment of these lesions can be invasive and change the appearance of older adults ${ }^{14-16}$. Melanoma can cause higher mortality and although it can occur at any time in life, studies indicate that sun exposure at any time can increase its likelihood ${ }^{14-17}$.

In addition, $46.25 \%$ of the older adults said they did not use sunscreen, one of the ways to care for the skin and protect from exposure. The fact that $26.25 \%$ of the older adults did not know what skin cancer is can justify the lack of care in relation to protection from the sun, because, in general, people are more engaged in preventive attitudes if they know about the damage and/or risks ${ }^{18}$. Sun exposure also causes other changes such as, for example, solar elastosis ${ }^{3}$ which translates into increased fragmentation and porosity of the elastic fibers in the dermis ${ }^{19,20}$.

In relation to skin hydration, it was observed that almost half of the evaluated population (42.5\%) did not use any type of moisturizer, which is worrying, as hydration is an important form of skin care for older adults, who may be more xerotic ${ }^{21}$.

The presence of melanosis was relatively prevalent in both sexes. Dermatological literature points to the high prevalence of this disorder in older adults, as it represents the translation of the accumulation of sun exposure throughout life $\mathrm{i}^{5,10,22-28}$. It is not a malignant or pre-malignant lesion, but causes aesthetic discomfort for many older people.

The presence of xerosis was observed in almost $60 \%$ of the older adults, and was higher in males, which goes against previous studies that found an incidence of $39.8 \%{ }^{4}$ and $58.6 \%{ }^{29}$. The study by Jindal et al. ${ }^{28}$ in India points to a lower prevalence of agerelated skin disorders when considering xerosis, senile purpura and solar melanosis in older adults, probably due to the higher prevalent phototype of the specific population studied. 
Most older people had only one comorbidity, with hypertension being the most frequent, corroborating previous studies ${ }^{4,29-31}$, followed by diabetes, thyroid disease and smoking. The most prevalent phototype was type 4 and the majority had three or more skin disorders, the most prevalent being melanosis, followed by xerosis, keratosis, onychomycosis, senile purpura, tinea, acrochordon and carcinomas.

Medical literature describes how diabetes can worsen skin quality and predispose the individual to the appearance of ulcers and other lesions ${ }^{4}$. In the present study, an association was observed between diabetes and keratosis.

Arterial hypertension was the most prevalent comorbidity, with 29 older men and 26 older women presenting the disease. In relation to other comorbidities, women suffer from this condition more. Studies show that hypertension may be related to skin disorders ${ }^{24}$. However, in the present study, no association was found between this comorbidity and skin diseases. An association was observed between diabetes and keratosis. Medical literature describes how diabetes can worsen skin quality and predispose the individual to the appearance of ulcers and other lesions.

In the present study, the prevalence of skin disorders relating to the natural aging process (xerosis, purple and melanosis) was higher than the prevalence of comorbidities, despite the exposure of the older adults to the sun until $10 \mathrm{am}$. However, sun exposure throughout life was not evaluated, which may corroborate the prevalence of benign skin changes also associated with the use of moisturizers.

Furthermore, the results of the present study suggest the need for better guidance in relation to skin care by health professionals, as a considerable

\section{REFERENCES}

1. Tuong W, Armstrong AW. Effect of appearance-based education compared with health-based education on sunscreen use and knowledge: a randomized controlled trial. Am Acad Dermatol. 2013;70(4):665-9. portion of the older adults in the sample were not provided with this type of information and, when they were received it from a dermatologist, or in other words, the focal specialist. Thus, further studies are needed that relate comorbidities to skin disorders in older adults so that a preventive plan can be implemented to minimize possible damage caused by excessive exposure to the sun and improve the quality of life of this population.

The limitations of the present study refer mainly to the absence of a history of sun exposure and skin care throughout the life of the studied population, since skin continuously exposed to ultraviolet radiation can exhibit cumulative damage that leads to the appearance of benign skin disorders.

\section{CONCLUSION}

Assessing the skin care of the older adults in the sample, it was concluded that, in general, both men and women were unaware of the dangers of exposing themselves to the sun and did not use sunscreen or moisturizers, habits that are part of the basic skin care in this age group.

The study population is in general low income and has low levels of education, living mostly in the municipality where the clinic is located, and the most prevalent skin phototype was type 4 .

The most prevalent dermatoses in the sample were melanosis, xerosis, purpura, keratosis and onychomycosis. These are common, benign dermatoses associated with the natural aging process, although solar melanosis can be avoided with proper use of sun protection.

Edited by: Ana Carolina Lima Cavaletti
2. Pegas LACS, Honorio SKA, Gonzalez VS, Crespo CL, Barreto BR, Nascimento HJ, et al. Dermatoses prevalentes em idosos atendidos em ambulatório de dermatologia de uma unidade básica de saúde (PoliclinicaUniFOA) de Volta Redonda, RJ, entre 2002 e 2010. Cad UniFOA. 2013;(ed. esp):39-44. 
3. Velarde MC, Demaria M. Targeting senescente cells: possible implications for delaying skin aging: a minireview. Gerontology. 2016;62(5):513-8.

4. Mendes AL, Miot HA, Haddad Junior V. Diabetes mellitus e pele. An Bras Dermatol. 2017;92(1):8-19.

5. Neumaier W, Neumaier LFT, Turchiello CM, Lampert MA. Prevalencia de las dermatoses y comorbilidades em ancianos en un ambulatório de dermatología. Rev Argent Dermatol. 2018;99(2):1-10.

6. Reske R, Pelka D, Walasek A, Machaj Z, Reich A. Skin disorders in elderly subjects. Int J Dermatol. 2015;54:332-8.

7. Dean AG, Sullivan KM, Soe MM. OpenEpi: Open Source Epidemiologic Statistics for Public Health. Version 3.01 [Internet]. 2013 [atualizado em 06 abr. 2013; acesso em 23 mar. 2020]. Disponível em: www. OpenEpi.com

8. Mattos e Dinato SL, Oliva R, Mattos e Dinato M, Macedo-Soares A, Bernardo WM. Prevalência de dermatoses em idosos residentes em instituição de longa permanência. Rev Assoc Med Bras. 2008;54(6):543-7.

9. Oliveira PK, Tosato MG, Alves RS, Martin AA, Fávero PP, Raniero L. Análise da composição bioquímica da pele por espectroscopia Raman. Rev Bras Eng Biomed. 2012;28(3):278-87.

10. Fitzpatrick TB. The validity and practicality of sunreactive skin types 1 through VI. Arch Dermatol. 1988;124(6):869-71.

11. Wollina U. Smoking and the skin. Skinmed. 2017;15(3):197-202.

12. Gu Y, Han J, Jiang C, Zhang Y. Biomarkers, oxidative stress and autophagy in skin aging. Ageing Res Rev. 2020;59:101036 [3 p.]

13. Bonté F, Girard D, Archambault JC, DErmoulière A. Skin changes during ageing. Subcell Biochem. 2019;91:249-80.

14. Alves JED. Transição demográfica, transição da estrutura etária e envelhecimento. Rev Port Divulg. 2014;40:8-15

15. Lenzi TCR, Reis CMS, Novaes MRCG. Perfil epidemiológico de idosos com neoplasia cutânea não melanoma assistidos em ambulatório de dermatologia de hospital público. An Bras Dermatol. 2017;92(6):887-9.

16. Silva LC, Pessanha AC, Saito DT, Mota IC, Steiner D. Índice diagnostico de neoplasia cutânea em campanha de combate ao câncer da pele em serviço dermatológico no interior do estado de São Paulo. Surg Cosmet Dermatol. 2017;9(4):314-5.

17. Berger TG, Steinhoff M. Pruritus in Elderly Patients: Eruptions of Senescence. Semin Cutan Med Surg. 2011;30(2):113-7.
18. Clark A, Hessler JL. Skin care. Facial Plast Surg Clin North Am. 2015;23(3):285-95.

19. Lo Turco IGS. Avaliação do conhecimento quanto ao câncer de pele e sua relação com exposição solar em alunos do SENAC de Aparecida de Goiânia. Rev Bras Geog Med Saúde. 2010;6(11):31-43.

20. Abadie S, Bedos P, Rouquette J. A human skin model to evaluate the protective effect of compounds against UVA damage. Int J Cosmet Sci. 2019;18(7):594-603.

21. Ikarashi N, Kon R, Kaneko M, Mizukami N, Kusunoki Y, Sugiyama K. Relationship between Aging-Related Skin Dryness and Aquaporins. Int J Mol Sci. 2017;18;18(7):1-10.

22. Sittart JAS, Zanardi HTF. Prevalência das dermatoses em pacientes da $4^{a}$ idade. Rev Soc Bras Clin Med. 2008;6(4)125-9.

23. Miguel LMZ, Jorge MFS, Rocha B, Miot HA. Incidência de dermatoses diagnosticadas em instituição pública: comparação entre 2003 e 2014. An Bras Dermatol. 2017;92(3):433-5.

24. Rodrigues NL, Mukamal RC. Doenças comuns do envelhecimento. In: Steiner D, Addor F. Envelhecimento Cutâneo. São Paulo: Ac Farmacêutica; 2014. pág. 74-85.

25. Alchorne MMA, Mateus A. Dermatoses associadas ao envelhecimento. In: Steiner D, Addor F. Envelhecimento Cutâneo. São Paulo: Ac Farmac; 2014. p. 87-97.

26. Goorochurn R, Viennet C, Granger C, Fanian F, Varin-Blank N, Roy CL, et al. Biological processes in solar lentigo: insights brought by experimental models. Exp Dermatol. 2016;25(3):147-7.

27. Reszke R, Pelka D, Walasek A, Machai Z, Reich A. Skin disordes in elderly subjects. Int J Dermatol. 2015;54(9):332-8.

28. Jindal R, Jain A, Roy S, Rawat SDS, Bhardwaj N. Skin Disorders Among Geriatric Population at a Tertiary Care Center in Uttarakhand. J Clin Diag Res. 2016;10(3):6-8

29. Reszke R, Pelka D, Walasek A, Machaj Z, Reich A. Skin disorders in elderly subjects. Int J Dermatol. 2015;54:332-8.

30. Tseng HW, Ger LP, Liang CK, Liou HH, Lam HC. High prevalence of cutaneous manifestations in the elderly with diabetes mellitus: an institutionbased cross-sectional study in Taiwan. J Eur Acad Dermatol Venereol. 2015;29(8):1631-5.

31. Raveendra L. A clinical study of geriatric dermatoses. Our Dermatol Online. 2014;5(3):235-9. 